BMJ Open

Diabetes

Research

\& Care

\section{Japanese radio calisthenics prevents the reduction of skeletal muscle mass volume in people with type 2 diabetes}

To cite: Kimura T, Okamura T, Iwai $\mathrm{K}$, et al. Japanese radio calisthenics prevents the reduction of skeletal muscle mass volume in people with type 2 diabetes. BMJ Open Diab Res Care 2020;8:e001027. doi:10.1136/ bmjdrc-2019-001027

Part of this manuscript has been published and presented in poster presentation of American Diabetes Association 79th Annual meeting of 2019 (752-P: Japanese radio calisthenics prevents reduction of skeletal muscle volume in patients with type 2 diabetes).

Received 7 November 2019 Revised 17 December 2019 Accepted 26 December 2019

Check for updates

(c) Author(s) (or their employer(s)) 2020. Re-use permitted under CC BY-NC. No commercial re-use. See rights and permissions. Published by BMJ.

Department of Endocrinolgy and Metabolism, Graduate School of Medical Science, Kyoto Prefectural University of Medicine, Kyoto, Japan

Correspondence to Dr Michiaki Fukui; michiaki@koto.kpu-m.ac.jp

\section{ABSTRACT}

Objective Reduction of muscle mass and strength is an important treatment target for patients with type 2 diabetes. Recent studies have reported that high-intensity resistance training improves physical function; however, all patients found it difficult to perform high-intensity resistance training. Radio calisthenics, considered as therapeutic exercises to promote health in Japan, are simple exercises that can be performed regardless of age and help move the muscles and joints of the whole body effectively according to the rhythm of radio. We investigated the efficacy of radio calisthenics for muscle mass in patients with type 2 diabetes in this retrospective cohort study.

Research design and methods A total of 42 hospitalized patients with type 2 diabetes were recruited. The skeletal muscle mass index $\left(\mathrm{SMl}, \mathrm{kg} / \mathrm{m}^{2}\right.$ ) was calculated as appendicular muscle mass $(\mathrm{kg})$ divided by height squared $\left(\mathrm{m}^{2}\right)$. We defined the change of SMI as the difference of SMI between the beginning and end of hospitalization. Results Among 42 patients, 15 (11 men and 4 women) performed radio calisthenics. Body weights of both radio calisthenics exercisers and non-exercisers decreased during hospitalization. The change of SMI was significantly lesser in radio calisthenics exercisers than in nonexercisers $(7.1 \pm 1.4$ to $7.1 \pm 1.3,-0.01 \pm 0.09$ vs $6.8 \pm 1.1$ to $\left.6.5 \pm 1.2,-0.27 \pm 0.06 \mathrm{~kg} / \mathrm{m}^{2}, \mathrm{p}=0.016\right)$. The proportion of decreased SMI was $85.2 \%$ (23/27 patients) in non-radio calisthenics exercisers, whereas that in radio calisthenics exercisers was $46.7 \%$ (7/15 patients).

Conclusions Radio calisthenics prevent the reduction of skeletal muscle mass. Thus, radio calisthenics can be considered effective for patients with type 2 diabetes.

\section{INTRODUCTION}

The number of patients with type 2 diabetes has been rapidly increasing, and these patients often suffer from a reduction of muscle mass and strength. ${ }^{1}$ The reduction of muscle volume and weakness of muscle tissues with ageing is called sarcopenia, which often leads to motor function disorders, falls, fractures, and difficulty in participating in activities of daily life. ${ }^{2}$ The presence of sarcopenia also increases the risk of chronic heart

\section{Significance of this study}

What is already known about this subject?

- Reduction of muscle mass and strength is an important treatment target for patients with type 2 diabetes.

- High-intensity resistance training improves physical function.

- Radio calisthenics, which is a Japanese traditional exercise, are simple exercises that can be performed regardless of age and can move the muscles and joints effectively.

What are the new findings?

- Skeletal muscle mass index (SMI, $\left.\mathrm{kg} / \mathrm{m}^{2}\right)$ and lean body mass decreased in non-radio calisthenics exercisers during hospitalization.

- The decrease of SMI was significantly lesser in radio calisthenics exercisers than in non-exercisers.

How might these results change the focus of research or clinical practice?

- Radio calisthenics are useful for maintaining skeletal muscle mass in patients with type 2 diabetes without adverse effects.

failure,${ }^{3}$ cardiovascular disease,${ }^{4}$ pneumonia,${ }^{5}$ and mortality. ${ }^{6}$

To maintain the human body's muscle volume, prolonged resistance training is required. ${ }^{7}$ Moreover, exercise can raise the efficiency of muscular glucose uptake because of an increase in muscle forkhead box protein $\mathrm{O}^{8}$ and glucose transporter $4,{ }^{9}$ which controls blood glucose levels. ${ }^{10}$ These rules are also applicable to patients with type 2 diabetes. ${ }^{9}$ Recent studies have reported that high-intensity resistance training improves physical function and balance ${ }^{11-13}$ and reduces the fear of falling. ${ }^{14}$ The American College of Sports Medicine and the American Diabetes Association demonstrated that resistance training enhanced the skeletal muscle volume and recommended a combination 
of aerobic and resistance training for controlling blood glucose levels. ${ }^{9}$ However, about half of the patients with diabetes did not perform the exercise regularly and a main reason for this was lack of time to exercise. ${ }^{10}$

In Japan, we habitually practice a Japanese traditional exercise called 'radio calisthenics'. These are simple exercises that can be performed regardless of age and can move the muscles and joints effectively according to the rhythm of the radio. It is considered a therapeutic exercise to promote health in Japan. The required time for calisthenics is approximately $3 \mathrm{~min}$, and it has an exercise intensity of 4-4.5 metabolic equivalents (METs). ${ }^{15}$ Radio calisthenics require a moderate-intensity aerobic activity that is considered to be suitable for the training of patients with type 2 diabetes. However, no studies have investigated the efficacy of radio calisthenics in patients with type 2 diabetes so far.

In addition, we have observed the reduction of muscle volume in patients with type 2 diabetes without prior physical inactivity during hospitalization for controlling blood glucose levels. Here, we investigated the efficacy of radio calisthenics for muscle mass in patients with type 2 diabetes in this retrospective cohort study.

\section{MATERIALS AND METHODS}

\section{Study patients}

We enrolled 42 patients with type 2 diabetes without physical inactivity who were all inpatients at the Kyoto Prefectural University of Medicine from April 2016 to March 2017. In this retrospective cohort study, 15 patients (11 men and 4 women), who were hospitalized from September 2016 to March 2017, practiced the radio calisthenics.

\section{Lifestyle factors and medications}

We administered a standardized questionnaire to all patients at the beginning of hospitalization. Patients were divided into non-smokers, ex-smokers, and current smokers. In addition, patients recorded the kinds and frequencies of their participation in sports or recreational activities in the questionnaire. ${ }^{16}$ We categorized patients who performed any kind of sports regularly at least once a week as regular exercisers. ${ }^{17}$ In addition, patients recorded the presence of drinking habits and insulin use on the questionnaire.

\section{Data collection}

At the beginning of hospitalization, patients underwent an examination of the concentrations of several factors in venous blood, including fasting plasma glucose, creatinine, and C-peptide after an overnight fast. Hemoglobin A1c (HbA1c) was measured using high-performance liquid chromatography, and results were expressed as a National Glycohemoglobin Standardization Program unit. We used the Japanese Society of Nephrology equation for estimated glomerular filtration rate (eGFR): eGFR $\left(\mathrm{mL} / \mathrm{min} / 1.73 \mathrm{~m}^{2}\right)=194 \times$ serum creatinine $\mathrm{e}^{-1.094} \times$ age $^{-0.287}$ $(\times 0.739$ for women $) .{ }^{18}$
Body composition of patients was evaluated using the body composition analyzer with a multifrequency impedance called InBody 720 (InBody Japan, Tokyo, Japan). ${ }^{19} 20$ The multifrequency impedance analyzer provided results that showed a good correlation with those obtained using the dual-energy X-ray absorptiometry method. ${ }^{21}$ We collected data of body weight (BW, $\mathrm{kg}$ ), skeletal muscle mass $(\mathrm{kg})$, appendicular muscle mass $(\mathrm{kg})$, and body fat mass $(\mathrm{kg})$. Then, skeletal muscle mass index (SMI, kg/ $\mathrm{m}^{2}$ ) was calculated by dividing the appendicular muscle mass $(\mathrm{kg})$ by the square of the height $(\mathrm{m}) .{ }^{22}$ Weightadjusted SMI was derived by dividing skeletal muscle mass $(\mathrm{kg})$ by the BW $(\mathrm{kg})$. Body mass index was defined as BW $(\mathrm{kg})$ by dividing the square of the height $(\mathrm{m})$. We investigated the body composition twice, once at the beginning and then at the end of hospitalization, and analyzed the difference between the values at two points. We defined the change of SMI as the difference of SMI between the beginning and end of the hospitalization. We also defined decreased SMI as a change of SMI of $<0 \mathrm{~kg} / \mathrm{m}^{2}$.

Retinopathy was assessed by chart review and graded as follows: no diabetic retinopathy, simple diabetic retinopathy, and proliferative diabetic retinopathy. ${ }^{23}$ Neuropathy was diagnosed using criteria for diabetic neuropathy proposed by the Diagnostic Neuropathy Study Group. ${ }^{24}$ Nephropathy was graded as follows: normoalbuminuria, urinary albumin excretion $<30 \mathrm{mg} / \mathrm{g}$ of creatinine $(\mathrm{Cr})$ (mg/gCr); microalbuminuria, $30-300 \mathrm{mg} / \mathrm{gCr}$; and macroalbuminuria, $>300 \mathrm{mg} / \mathrm{gCr}^{25}$

\section{Performance of radio calisthenics}

Radio calisthenics were established for improving people's physical strength and promoting public health by Japan post in the 1950s and have been popular among many people regardless of age or sex in Japan. Radio calisthenics have two types: the first radio calisthenics involves moving muscles and joints of the whole body to the rhythm, and the second radio calisthenics is aimed to improve muscle strength. We adopted the second radio calisthenics in this study. The required time for the calisthenics is approximately $3 \mathrm{~min}$, and it has an exercise intensity of 4.5 METs.

The duration of hospitalization was approximately 14 days, and we instructed the patients to perform the second radio calisthenics twice daily, once before breakfast and once after dinner on the bedside, during hospitalization. The training scheme of radio calisthenics was in accordance with a movie on DVD. We did not instruct any resistance training other than the radio calisthenics and aerobic training, mainly fast walking, for a total of $60 \mathrm{~min} /$ day. ${ }^{26}$

\section{Meals during hospitalization}

The meals served to the hospitalized patients were set as follows: total energy was calculated as ideal $\mathrm{BW} \times 25-30$ $\mathrm{kcal} / \mathrm{kg} \mathrm{BW} /$ day; carbohydrates comprised 50\%-60\% of the total energy; protein $1.0-1.2 \mathrm{~g} / \mathrm{kg} \mathrm{BW} /$ day; and the rest as fat, according to the recommendations of the 
Table 1 Characteristics of patients at the beginning of hospitalization

\begin{tabular}{|c|c|c|c|}
\hline & Radio calisthenics (-) & Radio calisthenics (+) & $P$ value \\
\hline Total number & 27 & 15 & - \\
\hline Male & $13(48.1)$ & $11(73.3)$ & 0.11 \\
\hline Age (years) & $65.8 \pm 12.6$ & $62.9 \pm 14.5$ & 0.50 \\
\hline Weight $(\mathrm{kg})$ & $64.1 \pm 16.3$ & $70.8 \pm 19.4$ & 0.24 \\
\hline Body mass index $\left(\mathrm{kg} / \mathrm{m}^{2}\right)$ & $24.6 \pm 4.8$ & $26.4 \pm 7.9$ & 0.37 \\
\hline Diabetes duration (years) & $14.5 \pm 9.0$ & $12.2 \pm 8.5$ & 0.44 \\
\hline $\mathrm{HbA1c}(\%)$ & $9.3 \pm 1.8$ & $10.2 \pm 1.2$ & 0.10 \\
\hline $\mathrm{HbA} 1 \mathrm{c}(\mathrm{mmol} / \mathrm{mol})$ & $77.8 \pm 19.4$ & $87.8 \pm 13.1$ & 0.10 \\
\hline FBS (mg/dL) & $167.7 \pm 51.5$ & $156.3 \pm 32.3$ & 0.44 \\
\hline C-peptide (nmol/L) & $1.4 \pm 0.8$ & $1.7 \pm 1.4$ & 0.29 \\
\hline Creatinine (mg/dL) & $0.73 \pm 0.2$ & $0.77 \pm 0.2$ & 0.63 \\
\hline eGFR $\left(\mathrm{mL} / \mathrm{min} / 1.73 \mathrm{~m}^{2}\right)$ & $77.8 \pm 23.5$ & $80.5 \pm 27.2$ & 0.74 \\
\hline $\mathrm{SMI}\left(\mathrm{kg} / \mathrm{m}^{2}\right)$ & $6.8 \pm 1.1$ & $7.1 \pm 1.4$ & 0.92 \\
\hline Weight-adjusted SMI & $0.587 \pm 0.080$ & $0.572 \pm 0.096$ & 0.61 \\
\hline Lean body mass $(\mathrm{kg})$ & $23.3 \pm 5.3$ & $25.2 \pm 6.8$ & 0.32 \\
\hline Right arm (kg) & $2.3 \pm 0.6$ & $2.4 \pm 0.9$ & 0.51 \\
\hline Left arm $(\mathrm{kg})$ & $2.2 \pm 0.6$ & $2.4 \pm 0.9$ & 0.40 \\
\hline Trunk (kg) & $19.4 \pm 4.1$ & $20.6 \pm 5.4$ & 0.42 \\
\hline Right leg (kg) & $6.6 \pm 1.6$ & $7.3 \pm 2.1$ & 0.26 \\
\hline Left leg $(\mathrm{kg})$ & $6.6 \pm 1.6$ & $7.3 \pm 2.0$ & 0.20 \\
\hline Body fat mass $(\mathrm{kg})$ & $20.4 \pm 9.9$ & $23.7 \pm 13.3$ & 0.38 \\
\hline Drinking habits & $13(48.1)$ & $2(13.3)$ & 0.96 \\
\hline Smoking states & & & 0.96 \\
\hline Ex-smoker & $9(33.3)$ & $6(40)$ & \\
\hline Current smoker & $7(25.9)$ & $2(13.3)$ & \\
\hline Exercise habits & $5(18.5)$ & $2(13.3)$ & 0.65 \\
\hline Insulin treatments & $8(29.6)$ & $4(26.7)$ & 0.35 \\
\hline Retinopathy (NDR/SDR/PDR) & $19(70.4) / 5(18.5) / 3(11.1)$ & $8(53.3) / 3(20.0) / 4(13.7)$ & 0.20 \\
\hline Nephropathy (normo/micro/macroalbuminuria) & $12(44.4) / 12(44.4) / 3(11.1)$ & $10(66.7) / 2(13.3) / 3(20)$ & 0.12 \\
\hline Neuropathy & $12(44.4) / 13(48.1)$ & $6(40) / 9(60)$ & 0.62 \\
\hline
\end{tabular}

Data are expressed as $\mathrm{n}(\%)$ or mean \pm SD. Weight-adjusted SMI was defined as dividing skeletal muscle mass by the body weight. $\mathrm{P}$ values by Welch's t-test for continuous variables and $\chi^{2}$ test for categorical variables.

eGFR, estimated glomerular filtration rate; FBS, fasting blood sugar; NDR, no diabetic retinopathy; PDR, proliferative diabetic retinopathy; SDR, simple diabetic retinopathy; SMI, skeletal muscle mass index.

Japanese Diabetes Society on dietetic therapy in Japanese patients with diabetes. ${ }^{27}$ Moreover, patients were not allowed to take snacks or supplements other than the meals served during hospitalization.

\section{Statistical analysis}

Statistical analyses were performed using JMP V.12.0 software (SAS Institute, Cary, North Carolina). A p value of $<0.05$ was considered statistically significant. The means or frequencies of potential confounding variables were calculated. Continuous variables were presented as mean $\pm \mathrm{SD}$. Categorical variables were presented as numbers (percentage, \%). P values were analyzed using the MannWhitney $\mathrm{U}$ test for continuous variables, and $\chi^{2}$ test for categorical variables was employed to assess the statistical significance of differences between the groups. Moreover, a paired t-test was performed to assess the statistical significance of differences between the beginning and end of the hospitalization. Then, we also analyzed the difference of change in SMI of patients with and without radio calisthenics according to the having exercise habit or not.

\section{RESULTS}

Clinical characteristics of the 42 patients (24 men and 18 women) who participated in the survey are shown in table 1 . 


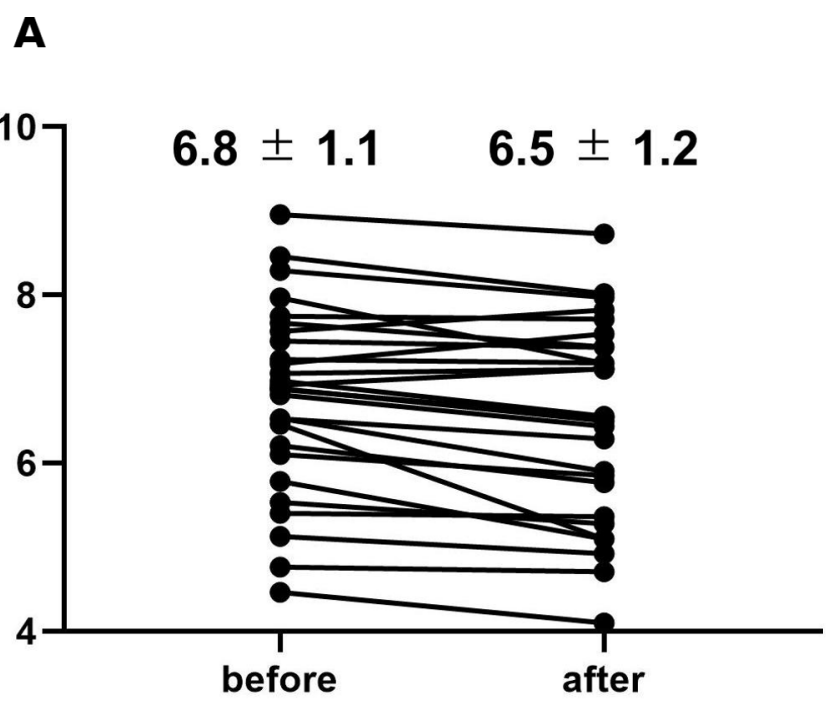

B

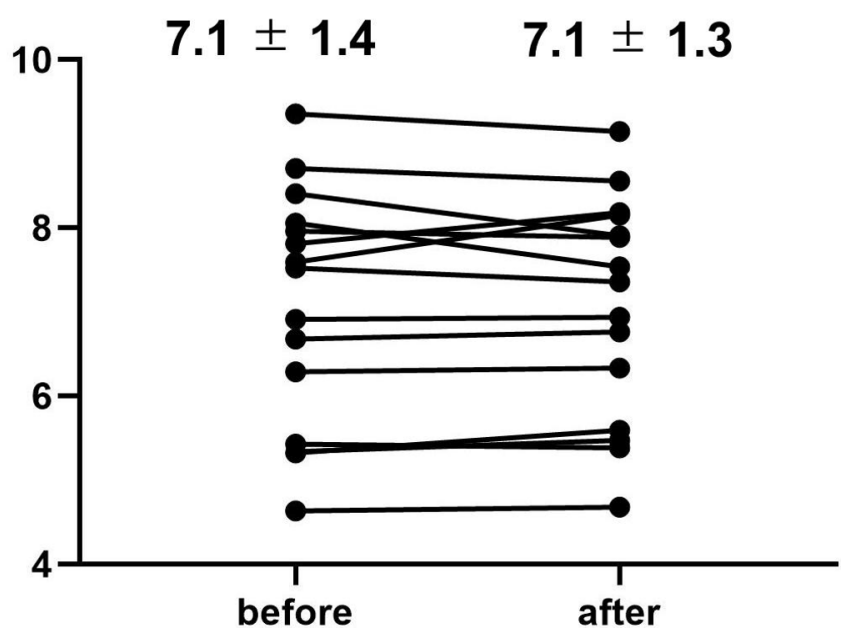

Figure 1 Change of SMI between $(A)$ non-radio calisthenics exercisers and $(\mathrm{B})$ radio calisthenics exercisers and during the hospitalization. SMI, skeletal muscle mass index.
Among them, 15 (11 men and 4 women) performed radio calisthenics during hospitalization. The average age of patients who did not exercise and those who exercised was $65.8 \pm 12.6$ and $62.9 \pm 14.5$ years, respectively. HbA1c levels in patients who did not exercise and in those who exercised were $9.3 \% \pm 1.8 \%$ and $10.2 \% \pm 1.2 \%$, respectively. Every night during hospitalization, we asked the patients whether they had performed the radio calisthenics, and we confirmed that all of them have certainly done it twice a day.

The change of SMI $\left(\mathrm{kg} / \mathrm{m}^{2}\right)$ is shown in figure 1 and table 2. BWs of both non-radio calisthenics exercisers and radio calisthenics exercisers decreased during hospitalization, whereas SMI and lean body mass decreased in non-radio calisthenics exercisers but not in radio calisthenics exercisers during hospitalization. The change of SMI was significantly lesser in radio calisthenics exercisers than in non-radio calisthenics exercisers $\left(-0.01 \pm 0.00\right.$ vs $\left.-0.27 \pm 0.06 \mathrm{~kg} / \mathrm{m}^{2}, \mathrm{p}=0.016\right)$. The proportion of decreased SMI was $85.2 \%$ (23/27 patients) in non-radio calisthenics exercisers, whereas that in radio calisthenics exercisers was $46.7 \%$ (7/15 patients). Moreover, weights of appendicular skeletal and upper limb muscles significantly increased in radio calisthenics exercisers compared with those in non-radio calisthenics exercisers. In contrast, weight reduction of the lower limb muscles tended to be lesser in the radio calisthenics exercisers than in non-radio calisthenics exercisers. Fat content in the radio calisthenics exercisers was significantly decreased compared with non- radio calisthenics exercisers (table 2).

In patients without exercise habit, the change in SMI of the patients with radio calisthenics tended to be lesser than that of patients without $\left(-0.07 \pm 0.26 \mathrm{~kg} / \mathrm{m}^{2}\right.$ vs $\left.-0.25 \pm 0.34 \mathrm{~kg} / \mathrm{m}^{2}, \mathrm{p}=0.168\right)$. In addition, in patients with exercise habit, the change in SMI of the patients with radio calisthenics was lesser than that of patients without $\left(-0.12 \pm 0.33 \mathrm{~kg} / \mathrm{m}^{2}\right.$ vs $\left.-0.30 \pm 0.37 \mathrm{~kg} / \mathrm{m}^{2}, \mathrm{p}=0.047\right)$.

Table 2 Characteristics of patients at the beginning and end of hospitalization

\begin{tabular}{|c|c|c|c|c|c|c|c|c|c|}
\hline & \multicolumn{4}{|c|}{ Radio calisthenics (-) } & \multicolumn{5}{|c|}{ Radio calisthenics (+) } \\
\hline & Beginning & End & Change & P value* & Beginning & End & Change & P value* & P value† \\
\hline Weight (kg) & $64.1 \pm 16.3$ & $62.4 \pm 15.2$ & $-1.66 \pm 0.40$ & $<0.001$ & $70.8 \pm 19.4$ & $69.2 \pm 18.0$ & $-1.55 \pm 0.53$ & 0.030 & 0.861 \\
\hline Body mass index $\left(\mathrm{kg} / \mathrm{m}^{2}\right)$ & $24.6 \pm 4.8$ & $24.1 \pm 4.5$ & $-0.62 \pm 0.13$ & $<0.001$ & $26.4 \pm 7.9$ & $25.8 \pm 7.5$ & $-0.56 \pm 0.18$ & 0.021 & 0.789 \\
\hline $\mathrm{SMI}\left(\mathrm{kg} / \mathrm{m}^{2}\right)$ & $6.8 \pm 1.1$ & $6.5 \pm 1.2$ & $-0.27 \pm 0.06$ & $<0.001$ & $7.1 \pm 1.4$ & $7.1 \pm 1.3$ & $-0.01 \pm 0.09$ & 0.914 & 0.016 \\
\hline Weight-adjusted SMI & $0.37 \pm 0.05$ & $0.37 \pm 0.05$ & $0.00 \pm 0.01$ & 0.708 & $0.36 \pm 0.06$ & $0.37 \pm 0.06$ & $0.01 \pm 0.01$ & $<0.001$ & 0.003 \\
\hline Lean body mass $(\mathrm{kg})$ & $23.3 \pm 5.3$ & $22.7 \pm 5.2$ & $-0.58 \pm 0.15$ & $<0.001$ & $25.2 \pm 6.8$ & $25.4 \pm 6.6$ & $-0.54 \pm 0.52$ & 0.532 & 0.210 \\
\hline Right arm (kg) & $2.3 \pm 0.6$ & $2.2 \pm 0.6$ & $-0.09 \pm 0.02$ & $<0.001$ & $2.4 \pm 0.9$ & $2.5 \pm 0.8$ & $0.04 \pm 0.03$ & 0.316 & 0.003 \\
\hline Left arm $(\mathrm{kg})$ & $2.2 \pm 0.6$ & $2.2 \pm 0.6$ & $-0.08 \pm 0.02$ & $<0.001$ & $2.4 \pm 0.9$ & $2.5 \pm 0.9$ & $0.06 \pm 0.03$ & 0.122 & 0.001 \\
\hline Trunk (kg) & $19.4 \pm 4.1$ & $19.0 \pm 4.1$ & $-0.43 \pm 0.12$ & $<0.001$ & $20.6 \pm 5.4$ & $20.9 \pm 5.3$ & $0.28 \pm 0.16$ & 0.170 & 0.001 \\
\hline Right leg (kg) & $6.6 \pm 1.6$ & $6.4 \pm 1.8$ & $-0.22 \pm 0.07$ & 0.003 & $7.3 \pm 2.1$ & $7.2 \pm 2.0$ & $-0.05 \pm 0.09$ & 0.591 & 0.136 \\
\hline Left leg $(\mathrm{kg})$ & $6.6 \pm 1.6$ & $6.2 \pm 1.8$ & $-0.32 \pm 0.13$ & 0.040 & $7.3 \pm 2.0$ & $7.2 \pm 2.0$ & $-0.07 \pm 0.17$ & 0.426 & 0.250 \\
\hline Body fat mass $(\mathrm{kg})$ & $20.4 \pm 9.9$ & $20.1 \pm 1.8$ & $-0.30 \pm 0.24$ & 0.282 & $23.7 \pm 13.3$ & $22.7 \pm 13.3$ & $-1.01 \pm 0.32$ & $<0.001$ & 0.039 \\
\hline
\end{tabular}

Data are mean $\pm S D$. Change was defined as the difference of SMI between the beginning and end of the hospitalization.

${ }^{*} P$ values are evaluated by paired $t$-test.

†P values are evaluated by Mann-Whitney $U$ test.

SMI, skeletal muscle mass index. 
There were no adverse effects related to the radio calisthenics, such as hypoglycemia, fall, fracture, and musculoskeletal pain.

\section{DISCUSSION}

Our study showed clear effects of radio calisthenics on muscle mass in hospitalized patients with type 2 diabetes. The change of SMI was significantly lesser in radio calisthenics exercisers. Weights of both appendicular skeletal muscles and upper limb muscles increased in radio calisthenics exercisers. Our past experience demonstrated that muscle volume reduces due to long-term hospitalization. In fact, about $85 \%$ of patients who did not perform radio calisthenics showed reduced muscle mass during hospitalization in this study. As a part of the treatment for patients with type 2 diabetes during hospitalization, it was necessary to determine an easy exercise therapy that could prevent reduction of skeletal muscle mass. In this study, we revealed that performing the radio calisthenics twice a day could help in maintaining the muscle mass of hospitalized patients.

Our study showed that radio calisthenics is associated with maintaining muscle mass in hospitalized patients with type 2 diabetes and helps in moving the appendicular skeletal muscles effectively. Exercise training improves insulin sensitivity in the skeletal muscles by increasing the muscular glucose uptake. ${ }^{9}$ Despite the simple procedures, it guarantees an exercise intensity of 4.5 METs and improves the glycemic control among patients with type 2 diabetes. Moreover, maintaining muscle mass prevents the deterioration of type 2 diabetes and the development of sarcopenia. ${ }^{1}$ In addition, there were no adverse effects related to the radio calisthenics.

A previous report revealed that people, who perform radio calisthenics more than 5 days a week for more than 3 years, were superior in muscle mass quantity, index of subclinical atherosclerosis and lung function compared with general population. ${ }^{28}$ Moreover, a previous study reported that radio calisthenics is the second exercise therapy followed by walking in Japanese outpatients with diabetes, ${ }^{29}$ and radio calisthenics is very popular in Japan. We also revealed that radio calisthenics is useful for preventing reduction of skeletal muscle mass more in patients with exercise habit than in patients without. This might be because many patients with exercise habit performed walking in Japan, ${ }^{29}$ one of the aerobic exercises; thus the patients with exercise habit can prevent decreasing SMI through obtaining both aerobic and resistance training effect.

Additionally, we could not demonstrate the association between the performance of radio calisthenics and improvement of glucose control. In this study, there was no significant difference between radio calisthenics and glucose control $(37.0 \pm 69.6 \mathrm{mg} / \mathrm{dL}$ vs $31.3 \pm 52.2 \mathrm{mg} /$ $\mathrm{dL}, \mathrm{p}=0.784)$. A possible explanation is that pharmacotherapy is a major factor affecting blood glucose, especially during hospitalization, and thus no significant difference in blood glucose improvement was detected between two groups. Additionally, because radio calisthenics is mainly resistance training, there is a possibility that radio calisthenics did not contribute to improving short-term glycemic control during hospitalization.

There was no incidence of hypoglycemia associated with radio calisthenics in this study. However, during hospitalization, the blood glucose of the patients has been checked at least four times a day, before every meal and at bedtime, and we have checked them every day and adjusted insulin and oral antidiabetic drugs appropriately in order to prevent hypoglycemia, which might result in the finding.

There are several limitations to this study that have to be mentioned. First, this study was not a randomized controlled trial, but a retrospective cohort study. Therefore, some bias might exist. To clarify the effect of radio calisthenics on skeletal muscle mass, further studies, especially randomized controlled trials, would be needed. Second, the study population consisted only of Japanese. Thus, it is unclear whether the same results can be obtained in the Western population with different physiques. Third, the sample size was not large. Fourth, we did not follow-up the data of body composition after discharge. Therefore, the long-term effect of radio calisthenics remains unclear. Additionally, we could not demonstrate the association between the performance of radio calisthenics and improvement of glucose control. In this study, there was no significant difference between radio calisthenics and glucose control $(37.0 \pm 69.6 \mathrm{mg} /$ $\mathrm{dL}$ vs $31.3 \pm 52.2 \mathrm{mg} / \mathrm{dL}, \mathrm{p}=0.784)$. In this point, further studies would be needed as well. Lastly, because we used data using a body composition analyzer with a multifrequency impedance, change of body water balance might affect this result.

In conclusion, our study showed the effect of radio calisthenics on skeletal muscle mass in patients with type 2 diabetes. In order to elucidate this causal relationship, further accurate analyses, such as a randomized controlled trial, will be required.

Acknowledgements We thank Editage (www.editage.com) for English language editing.

Contributors TK designed the study, analyzed the data and wrote the manuscript. T0 designed the study, researched, analyzed and interpreted the data and reviewed/edited the manuscript. YH researched and interpreted the data and contributed to discussion. KI, TS, EU, MH, MA and MY researched the data and contributed to discussion. MF interpreted the data and reviewed/edited the manuscript. MF is the guarantor of this work and, as such, had full access to all the data in the study and takes responsibility for the integrity of the data and the accuracy of the data analysis.

Funding The authors have not declared a specific grant for this research from any funding agency in the public, commercial or not-for-profit sectors.

Disclaimer The sponsors were not involved in the study design, in the collection, analysis, or interpretation of data, in the writing of this manuscript, or in the decision to submit the article for publication.

Competing interests $\mathrm{YH}$ has received grant support from Asahi Kasei Pharma and honoraria from Mitsubishi Tanabe Pharma and Novo Nordisk Pharma, outside the submitted work. TS has received payment for development of educational presentation from Ono Pharmaceutical, Mitsubishi Tanabe Pharma, Astellas 
Pharma, Kyowa Hakko Kirin, Sanofi, MSD, Kowa Pharmaceutical, Taisho Toyama Pharmaceutical, Takeda Pharmaceutical, Kissei Pharmaceutical, Novo Nordisk Pharma and Eli Lilly Japan. MH has received grant support from Asahi Kasei Pharma, payment for development of educational presentations from MSD, Mitsubishi Tanabe Pharma, Kowa and Sumitomo Dainippon Pharma, and royalties from US 10,238,714 B2, outside the submitted work. EU has received personal fees from AstraZeneca, Astellas Pharma, Daiichi Sankyo, Kyowa Hakko Kirin, Kowa Pharmaceutical, MSD, Mitsubishi Tanabe Pharma, Novo Nordisk Pharma, Taisho Toyama Pharmaceutical, Takeda Pharmaceutical, Nippon Boehringer Ingelheim, Sumitomo Dainippon Pharma and Johnson \& Johnson, outside the submitted work. MA has received payment for development of educational presentation from Novo Nordisk Pharma, Abbott Japan, AstraZeneca, Kowa Pharmaceutical, Ono Pharmaceutical and Sumitomo Dainippon Pharma. MY has received payment for development of educational presentation from MSD, Sumitomo Dainippon Pharma, Kowa, AstraZeneca, Takeda Pharmaceutical, Kyowa Hakko Kirin, Daiichi Sankyo, Kowa Pharmaceutical, and Ono Pharmaceutical. MF has received research support and payment for development of educational presentation from AstraZeneca, Astellas Pharma, Nippon Boehringer Ingelheim, Daiichi Sankyo, Eli Lilly Japan, Kyowa Hakko Kirin, Kissei Pharmaceutical, MSD, Sumitomo Dainippon Pharma, Kowa, Mitsubishi Tanabe Pharma, Novo Nordisk Pharma, Sanwa Kagaku Kenkyusho, Sanofi, Ono Pharmaceutical, Taisho Pharmaceutical, Bayer Yakuhin, Mochida Pharmaceutical, Johnson \& Johnson Medical, Nippon Chemiphar, Terumo, Teijin Pharma, and Takeda Pharmaceutical.

Patient consent for publication Not required.

Ethics approval The Ethics Committee of Kyoto Prefectural University of Medicine approved this study (No RBMR-E-466-7). All people provided informed consent and written informed consent.

Provenance and peer review Not commissioned; externally peer reviewed.

Data availability statement Data are available upon reasonable request. The data sets used and/or analyzed during the current study are available from the corresponding author on reasonable request.

Open access This is an open access article distributed in accordance with the Creative Commons Attribution Non Commercial (CC BY-NC 4.0) license, which permits others to distribute, remix, adapt, build upon this work non-commercially, and license their derivative works on different terms, provided the original work is properly cited, appropriate credit is given, any changes made indicated, and the use is non-commercial. See: http://creativecommons.org/licenses/by-nc/4.0/.

ORCID iD

Yoshitaka Hashimoto http://orcid.org/0000-0002-8794-0550

\section{REFERENCES}

1 Leenders M, Verdijk LB, van der Hoeven L, et al. Patients with type 2 diabetes show a greater decline in muscle mass, muscle strength, and functional capacity with aging. J Am Med Dir Assoc 2013;14:585-92

2 Delmonico MJ, Harris TB, Lee J-S, et al. Alternative definitions of sarcopenia, lower extremity performance, and functional impairment with aging in older men and women. J Am Geriatr Soc 2007;55:769-74.

3 Okamura T, Hashimoto Y, Miki A, et al. High brain natriuretic peptide is associated with sarcopenia in patients with type 2 diabetes: a cross-sectional study of KAMOGAWA-DM cohort study. Endocr $J$ 2019;66:369-77.

4 Hashimoto Y, Kaji A, Sakai R, et al. Sarcopenia is associated with blood pressure variability in older patients with type 2 diabetes: a cross-sectional study of the KAMOGAWA-DM cohort study. Geriatr Gerontol Int 2018;18:1345-9.

5 Kaji A, Hashimoto Y, Kobayashi Y, et al. Sarcopenia is associated with tongue pressure in older patients with type 2 diabetes: a cross-sectional study of the KAMOGAWA-DM cohort study. Geriatr Gerontol Int 2019;19:153-8.

6 Cruz-Jentoft AJ, Baeyens JP, Bauer JM, et al. Sarcopenia: European consensus on definition and diagnosis: report of the European Working group on sarcopenia in older people. Age Ageing 2010;39:412-23.
7 Fiatarone MA, Marks EC, Ryan ND, et al. High-intensity strength training in nonagenarians. Effects on skeletal muscle. JAMA 1990;263:3029-34.

8 Azad M, Khaledi N, Hedayati M. Effect of acute and chronic eccentric exercise on FOXO1 mRNA expression as fiber type transition factor in rat skeletal muscles. Gene 2016;584:180-4.

9 Goodyear LJ, Kahn BB. Exercise, glucose transport, and insulin sensitivity. Annu Rev Med 1998;49:235-61.

10 Okamura T, Hashimoto Y, Osaka T, et al. The sodium-glucose cotransporter 2 inhibitor luseogliflozin can suppress muscle atrophy in $\mathrm{Db} / \mathrm{Db}$ mice by suppressing the expression of foxo1. J Clin Biochem Nutr 2019;65:23-8.

11 Liu C, Latham NK. Progressive resistance strength training for improving physical function in older adults. Cochrane Database Syst Rev 2009;3:CD002759.

12 Silva NL, Oliveira RB, Fleck SJ, et al. Influence of strength training variables on strength gains in adults over 55 years-old: a meta-analysis of dose-response relationships. J Sci Med Sport 2014;17:337-44.

13 Raymond MJ, Bramley-Tzerefos RE, Jeffs KJ, et al. Systematic review of high-intensity progressive resistance strength training of the lower limb compared with other intensities of strength training in older adults. Arch Phys Med Rehabil 2013;94:1458-72.

14 Kendrick D, Kumar A, Carpenter $\mathrm{H}$, et al. Exercise for reducing fear of falling in older people living in the community. Cochrane Database Syst Rev 2014;11:CD009848.

15 The Exercise and Physical Activity Reference for Health Promotion 2013. The Ministry of health labour and welfare of Japan (in Japanese). Available: https://www.mhlw.go.jp/content/000306883. pdf [Accessed 24 Jul 2019].

16 Osaka T, Hashimoto Y, Fukuda T, et al. Relationship between skeletal muscle mass and hepatic fibrosis in patients with type 2 diabetes. Diabetes Metab 2017;43:184-6.

17 Hashimoto Y, Hamaguchi M, Kojima T, et al. Modest alcohol consumption reduces the incidence of fatty liver in men: a population-based large-scale cohort study. J Gastroenterol Hepatol 2015;30:546-52

18 Matsuo S, Imai E, Horio M, et al. Revised equations for estimated GFR from serum creatinine in Japan. Am J Kidney Dis 2009;53:982-92.

19 Hashimoto Y, Osaka T, Fukuda T, et al. The relationship between hepatic steatosis and skeletal muscle mass index in men with type 2 diabetes. Endocr J 2016;63:877-84.

20 Okamura T, Miki A, Hashimoto Y, et al. Shortage of energy intake rather than protein intake is associated with sarcopenia in elderly patients with type 2 diabetes: a cross-sectional study of the KAMOGAWA-DM cohort. J Diabetes 2019;11:477-83.

21 Kim M, Shinkai S, Murayama $\mathrm{H}$, et al. Comparison of segmental multifrequency bioelectrical impedance analysis with dual-energy X-ray absorptiometry for the assessment of body composition in a community-dwelling older population. Geriatr Gerontol Int 2015;15:1013-22.

22 Chen L-K, Liu L-K, Woo J, et al. Sarcopenia in Asia: consensus report of the Asian Working group for sarcopenia. J Am Med Dir Assoc 2014:15:95-101.

23 Mineoka $Y$, Ishii M, Tsuji A, et al. Relationship between limited joint mobility of the hand and diabetic foot risk in patients with type 2 diabetes. J Diabetes 2017;9:628-33.

24 Tesfaye S, Boulton AJM, Dyck PJ, et al. Diabetic neuropathies: update on definitions, diagnostic criteria, estimation of severity, and treatments. Diabetes Care 2010;33:2285-93.

25 Hashimoto Y, Tanaka M, Senmaru T, et al. Heart rate-corrected QT interval is a novel risk marker for the progression of albuminuria in people with Type 2 diabetes. Diabet Med 2015;32:1221-6.

26 Boulé NG, Haddad E, Kenny GP, et al. Effects of exercise on glycemic control and body mass in type 2 diabetes mellitus: a metaanalysis of controlled clinical trials. JAMA 2001;286:1218-27.

27 4. Diet therapy. Treatment guide for diabetes 2016-2017. Tokyo, Japan: The Japan Diabetes Society.

28 Survey of the effects of radio calisthenics: summary version: 2013 radio calisthenics business research (in Japanese). Association of Postal Insurance 2014

29 Kamiya A, Ohsawa I, Fujii T, et al. A clinical survey on the compliance of exercise therapy for diabetic outpatients. Diabetes Res Clin Pract 1995;27:141-5. 